\title{
- Importância da mastite na produção leiteira do país
}

\section{- The importance of mastitis in dairy production in Brazil}

\author{
Elizabeth Oliveira da Costa - CRMV-SP n ${ }^{0} 0887$ \\ Professor Titular - FMVZ/USP \\ Coordenadora do NAPGAMA
}

Av.Prof.Dr. Orlando
Marques Paiva, 87
05508-000 - São Paulo
SP - Brasil
Tel. (011) 818-7651
Fax: (011) 818-7913
E-mail:
napgama@org.usp.br

Av.Prof.Dr. Orlando
Marques Paiva, 87

SP - Brasil

Tel. (011) 818-7651

E-mail:

\section{RESUMO}

A mastite, inflamação da glândula mamária, determina perdas econômicas decorrentes da redução na produção de leite, gastos com medicamentos e assistência veterinária, descarte de leite contaminado após tratamento e descarte de animais. A etiologia da mastite é bastante diversificada, sendo que os casos de importância econômica, são causados por microrganismos. Os principais agentes etiológicos foram agrupados quanto à sua origem e modo de transmissão em microrganismos contagiosos (Streptococcus agalactiae, Staphylococcus sp, e Corynebacterium bovis) transmitidos principalmente durante a ordenha e microrganismos ambientais (Streptococcus uberis, Enterobacteriaceae, fungos, algas do gênero Prototheca, etc.). A mastite clínica caracteriza-se por alterações visíveis da glândula e/ou do leite. A mastite subclínica se caracteriza pela diminuição da produção leiteira sem que sejam observados sinais de processo inflamatório. Os programas de controle de mastite tem como objetivo a limitação da prevalência da mastite a níveis economicamente aceitáveis dentro das circunstâncias particulares a cada propriedade. O programa baseia-se em quatro aspectos: fonte de infecção - diagnóstico, tratamento ou descarte; susceptível - nutrição, seleção de animais mais resistentes e higiene de ordenha; vias de transmissão - higiene de ordenha e meio ambiente; conscientização do problema aos produtores devido às perdas econômicas e educação sanitária dos tratadores e ordenhadores. O prejuízo por mastite estimado em propriedades brasileiras foi da ordem de \$332 dolares/vaca/ano, sendo superior ao observado em outros países (nos EUA, por exemplo, a média é de $\$ 200$ dolares/vaca/ano).

Unitermos: mastite, bovinos, glândula mamária, microrganismos, controle

\section{Introdução}

O termo mastite derivado do grego "mastos", glândula mamária e do sufixo "ite", inflamação, caracterizase por ser um processo inflamatório da glândula mamária ( Figura 1). Além da causa infecciosa, a mastite pode ter outras: traumática, metabólica, fisiológica (nos primeiros dias de lactação e na interrupção da lactação) alérgica e até mesmo psicológica, decorrente por exemplo da retenção de leite pela fêmea zebuína ou mestiça na ausência do bezerro (COSTA, 1991).

A mastite infecciosa é considerada a mais importante porque não é auto-limitante, podendo evoluir eventualmente para um quadro de septicemia. É contagiosa apresenta baixa porcentagem de cura espontânea. Além de representar um potencial risco a saúde do consumidor por veicular agentes etiológicos de zoonoses.

\section{Importância econômica}

Além dos aspectos ligados à saúde pública devese considerar que a mastite infecciosa é uma das principais causas de prejuízos na produção leiteira. Calcula-se que aproximadamente 17 a $20 \%$ da população mundial de vacas leiteiras em um dado momento tenham mastite (DU PREEZ \& GIESECKE, 1994). Estimativas feitas em vários países calculam perdas por esse processo da ordem de 10 a $15 \%$ da produção. Em 1987, por exemplo, os EUA perderam 8 bilhões de litros, o equivalente à produção brasileira no mesmo ano (COSTA, 1991). 
COSTA, ELIZABETH OLIVEIRA DA. Importância da mastite na produção leiteira do pais. Revista de Educação Continuada do CRMV-SP. São Paulo, fascículo 1, volume 1, p.003 - 009, 1998.

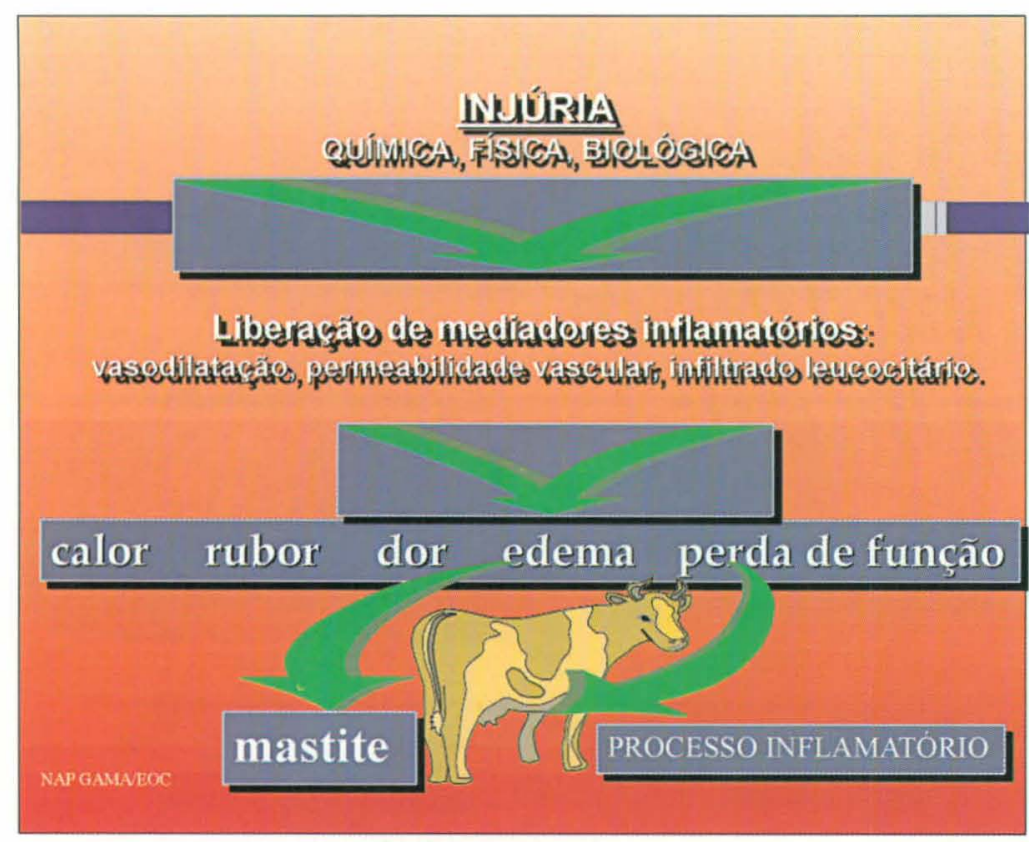

Figura 1 - Mastite: Processo Inflamatório da glândula mamária

PHILPOT, 1984 referiu uma estimativa de que $40 \%$ das vacas leiteiras apresentavam mastite subclínica em 1 ou mais quarto nos E.U.A. National Mastitis Council U.S. referiu um prejuizo de aproximadamente 200 dólares por vaca anualmente. Prejuizo, este, representado principalmente por: $70 \%$ de perda devido à redução na produção dos quartos com mastite subclínica; $8 \%$ pela perda por leite descartado por alteração e/ou pela presença de resíduos após tratamento; $8 \%$ pelos gastos com tratamentos, isto é, honorários de veterinários mais despesas com medicamentos; $14 \%$ por morte ou descarte animal, ou ainda pela desvalorização comercial do animal, por quartos afuncionais ou atrofiados. Nos Estados Unidos, de acordo com vários autores os prejuízos atingem a casa dos 2 bilhões de dólares anuais (CULLOR, 1993).

A redução na produção leiteira total é representada principalmente pela mastite subclínica (82\%). A mastite clínica representa apenas $18 \%$ do prejuizo total, por causar morte ou descarte prematuro. A redução na produção leiteira por quarto acometido por mastite subclínica é de 6 a $46 \%$ e de 5 a $84 \%$ por vaca afetada e causa ainda prejuízo pela alteração na qualidade do leite (DU PREEZ \& GIESECKE, 1994).

Uma vaca com mastite vai ter sua produção leiteira afetada em quantidade e qualidade. Observa-se um menor teor de lactose, caseína, gordura, cálcio e fósforo e um aumento de imunoglobulinas, cloretos e lipase (que leva ao ranço). O leite é inadequado para o consumo e produção de derivados podendo ser rejeitado na plataforma de usina. No Brasil em pesquisas (COSTA et al.1995a e COSTA et al, 1995b) referem que os índices de ocorrência de mastite subclinica é da ordem de $72 \%$ e $17.5 \%$ de mastite clínica, nos estados de Minas Gerais e São Paulo (Tabela 1). Os prejuízos por mastite subclínica em propriedades nestas mesmas regiões, por mastite corresponderam em média a $\$ 332,20$ por vaca/ano e $\$ 21.729,87$ por propriedade/ano (COSTA et al, 1998) Figura 2.

\section{Etiologia}

Até 1988, uma revisão de literatura (WATTS,1988) referia que 137 diferentes espécies de microrganismos participavam da etiologia da mastite bovina. Na atualidade poder-se-ia estimar mais de 150 espécies, mas os principais gêneros de microrganismos participantes da etiologia do processo menos de dez . Assim, os principais microrganismos agentes etiológicos de mastite foram convencionalmente agrupados quanto à sua origem e modo de transmissão em dois grupos: microrganismos contagiosos, transmitidos principalmente durante a ordenha, que são aqueles também chamados "vaca dependentes" presentes principalmente no corpo do animal com ou sem mastite e os chamados microrganismos ambientais, ubiquitários, presentes no ar, cama ("free-stall", etc), água e fezes. Estão classificados no primeiro grupo: Streptococcus agalactiae,

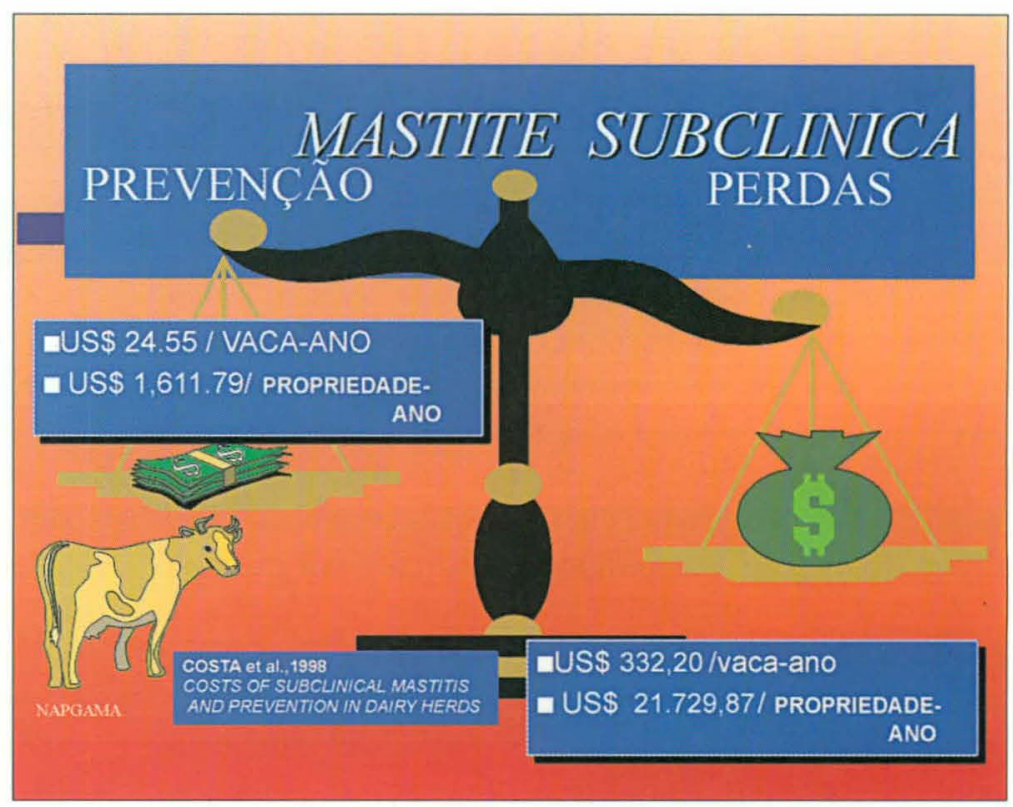

Figura 2 - Mastite Subclínica: prejuízos pela redução na produção de leite 


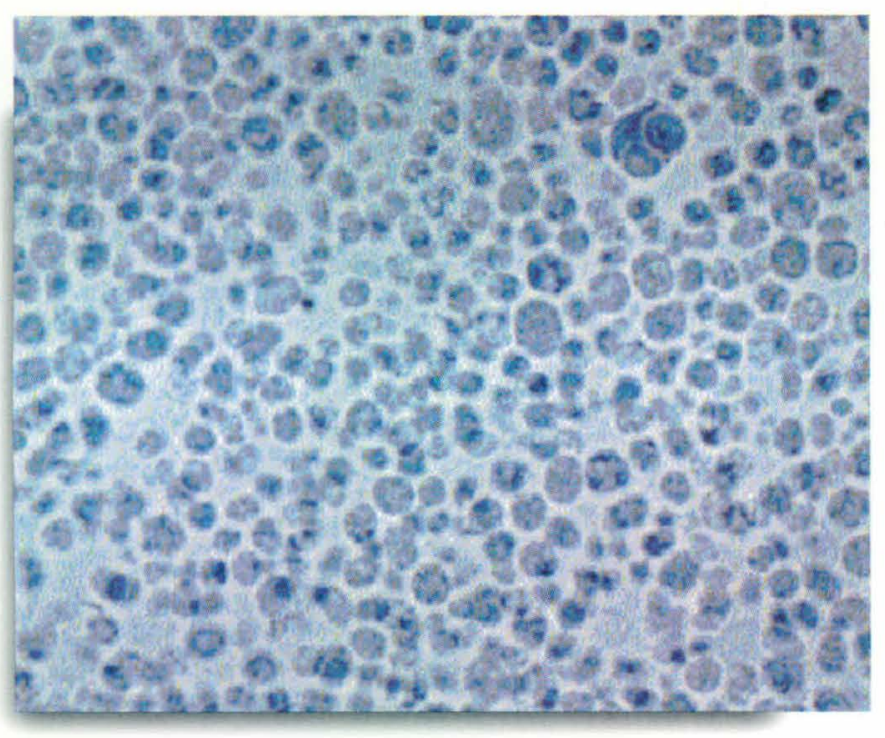

Figura 3 - Fotomicrografia de alga aclorofilada Prothoteca zopfii Coloração azul lactofenol algodão (400x).

Streptococcus dysgalactiae, Staphylococcus $\mathrm{sp}$, S.aureus e Corynebacterium bovis. No segundo grupo: Streptococcus uberis e os outros estreptococos à exceção dos acima citados, Enterobacteriaceae (Escherichia coli, Klebsiella sp, Serratia sp etc.), Actinomyces pyogenes, Pseudomonas sp e outros microrganismos ubiquitários tais como fungos, principalmente leveduras e algas aclorofiladas, do gênero Prototheca sp. (Figura 3 fotomicrografia Prototheca zopfii).

$\mathrm{Na}$ Tabela 1 estão agrupados principais agentes etiológicos de mastite isolados pelos pesquisadores do Núcleo de Apoio à Pesquisa em Glândula Mamária e Produção Leiteira (NAP GAMA) nas regiões de São Paulo e Minas Gerais (COSTA et al, 1997). De todos os pa-

Etiologia de Mastite Bovina: resultados de 31463 (SP) e 8146 (MG) amostras de leite, estudo em 127 propriedades leiteiras dos Estados de S. Paulo e M.Gerais Brasil.1997.

\begin{tabular}{|l|r|r|r|r|}
\hline \multirow{2}{*}{ Agentes etiológicos } & \multicolumn{2}{|c|}{ S. PAULO } & \multicolumn{2}{c|}{ MINAS GERAIS } \\
\cline { 2 - 5 } & № & $\%$ & № & $\%$ \\
\hline Staphylococcus sp & 8250 & 26 & 2285 & 28 \\
\hline Corynebacterium sp & 11526 & 37 & 3609 & 44 \\
\hline Streptococcus sp & 5796 & 18 & 1600 & 17 \\
\hline Enterobacteriaceae & 128 & 0,4 & 56 & 0,7 \\
\hline Algas & 744 & 2,4 & 57 & 0,7 \\
\hline Fungos & 242 & 0,8 & 48 & 0,6 \\
\hline Nocardia sp & 44 & 0,14 & 15 & 0,18 \\
\hline Outros & 108 & 0,34 & 15 & 0,18 \\
\hline NAP GAMA
\end{tabular}

Tabela 1 - Etiologia de mastite: porcentagem de ocorrência dos principais microorganismos contagiosos e ambientais. 1997. tógenos supra mencionados Staphylococcus sp é o mais freqüente seguido de Corynebacterium bovis e Streptococcus sp. As enterobactérias no País são causadoras de aproximadamente $5 \%$ dos casos de mastite, Pseudomonas sp. $2 \%$ e outras bactérias $6 \%$, entre estas destacaríamos Listeria monocytogenes, Brucella abortus, Nocardia asteroides, as quais muito embora ocorram em menor porcentagem dos casos são agentes de zoonoses graves. A primeira, Listeria monocytogenes, causa meningoencefalite, septicemia, abortamento e tem por característica a capacidade de se multiplicar à temperatura de refrigeração do leite ( 0 a $4{ }^{\circ} \mathrm{C}$ ), sendo citados casos na literatura internacional de surtos atribuídos ao consumo de leite pasteurizado. Enquanto que a última citada, $N$.asteroides, causa micetomas e granulomas em diversos orgãos, e em alguns estudos tem apresentado resistência às temperaturas e tempos empregados na pasteurização do leite (COSTA et al, 1996).

A mastite micótica apresentava alta freqüência, $11 \%$ de acordo com os resultados de levantamentos realizados em propriedades leiteiras de São Paulo e Minas Gerais (COSTA et al. 1986, 1993), frequência apenas encontrada na África do Sul, nos estudos mais recentes realizados nas mesmas regiões, tem-se apresentado em níveis de ocorrência mais baixos, demonstrando uma maior conscientização do problema e maior assepsia nos tratamento intramamários, um menor uso de corticoesteróides na composição destes medicamentos.

\section{Características clínicas}

A mastite clínica caracteriza-se por alterações visíveis da glândula e/ou do leite. Pode ser aguda apresentando sintomatologia evidente de processo inflamatório (edema, dor, calor, rubor) com ou sem alterações da característica de leite. Já na mastite crônica observa-se fibrosamento, ausência dos sinais de processo inflamatório e alterações no leite, grumos, coagulos,etc. De sintomatologia não tão evidente, a mastite subclínica se caracteriza pela diminuição da produção leiteira sem que contudo se observem sinais de processo inflamatório ou fibrosamento.

Estes diferentes tipos de manifestações clínicas estão na dependência da interação de fatores ligados ao hospedeiro, a vaca leiteira e ao microrganismo. Bactérias como o $S$. aureus, por exemplo, se ligam à fibronectina, facilitando a sua persistência na glândula, geralmente estão associadas à mastite subaguda ou crônica, classificada também pela escola hanoveriana, como mastite catarral, mas eventualmente pode determinar casos severos de mastite gangrenosa ou mesmo de natureza gra- 
nulomatosa, como na botriomicose. Outras, como as enterobactérias, (E. coli, Klebsiella sp,Serratia sp.) além de causar lesão nos alvéolos em decorrência da sua multiplicação na glândula mamária, produzem LPS (lipopolissacáride) que age como toxina (endotoxina), determinando uma mastite geralmente aguda, podendo levar ao choque endotóxico e morte do animal. Outros agentes, como Nocardia asteroides, N. brasiliensis e Actinomyces pyogenes levam à formação de granulomas ou abcessos intramamários, mastite classificada como apostematosa, que dificultam à ação dos antibióticos, constituindo mastites de difícil cura. Figura 4 (Foto de vaca com mastite clínica por A.pyogenes)

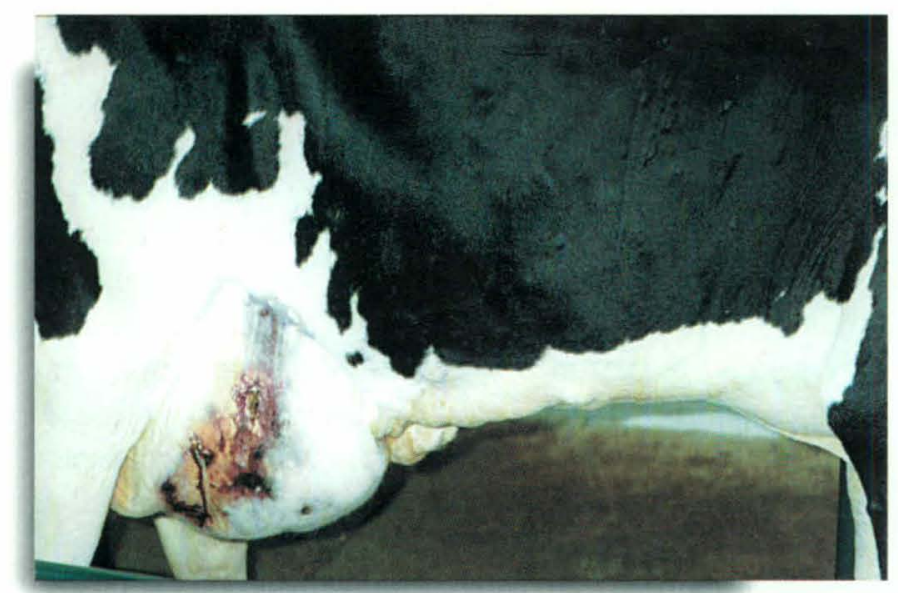

Figura 4 - Foto de vaca com mastite clínica por Actinomyces pyogenes

\section{Patogenia}

O estabelecimento dos microrganismos na glândula mamária e o conseqüente desencadeamento do processo inflamatório apresenta a seguinte seqüência de eventos: penetração- instalação - multiplicação.

Portanto, o estabelecimento de infecção por um determinado patógeno na glândula mamária depende de vários fatores ligados: ao microrganismo, ao hospedeiro, ao meio ambiente.

Fatores ligados aos microrganismos:

Fatores de Virulência

Entre estes destaca-se o fato de que multiplicamse bem no leite, o que indica que são capazes de usar lactose como fonte de carbono e/ou tem capacidade proteolítica, que lhes garante uma suplementação adequada de nitrogênio através da hidrólise de caseína. A habilidade de aderir ao epitélio, que possibilita não serem eliminados com os jatos de leite, facilitando colonização. Outros fatores de virulência têm importância favorecendo o estabelecimento da infecção, como por exemplo, presença de cápsula que dificultaria a fagocitose, presença de sideróforos na superfície das E. coli com ca- pacidade de quelar o ferro necessário para o seu metabolismo, portanto capacitando-a a competir com mecanismos de defesa inespecífica do hospedeiro, a lactoferrina.

Fatores ligados ao hospedeiro:

Mecanismos de defesa - Entre estes encontramse os fatores que impedem a penetração principalmente situados no teto e fatores que impedem a instalação. Portanto, estão diretamente relacionados à idade; às características do úbere, como tamanho, forma e tamanho dos tetos e tonicidade dos ligamentos; à integridade e perfeita oclusão dos canal do teto, e ainda, à sanidade e ao estado nutricional do animal.

A principal porta de entrada de patógenos é o orifício do teto. A via descendente (hematógena) é menos importante, mas é a via de disseminação nos casos de mastite intersticial crônica observada na brucelose, listeriose e na tuberculose.

Portanto, o canal do teto com boa oclusão é a barreira primária para a penetração de microrganismos na cisterna da glândula, consiste em barreira mecânica, além disso a presença de queratina, apresentam ação bactericida e bacteriostática, atua de três diferentes formas impedindo a penetração: 1 . Absorção das bactérias à queratina (com ação bactericida); 2. Pela eliminação do complexo queratina-bactéria; 3 . Pela renovação das células queratinizadas que formam quase um selo na extremidade do teto

Estes conhecimentos determninaram mudanças: na seleção genética de vacas leiteiras, a boa oclusão do orifício do teto tem sido considerada; nas práticas de tratamento intramamário, estudos tem demonstrado que o uso de cânulas curtas (3-4 mm) ou a introdução apenas da extremidade distal das cânulas comuns, resultaram em menores índices de ocorrência de infecções intramamárias.

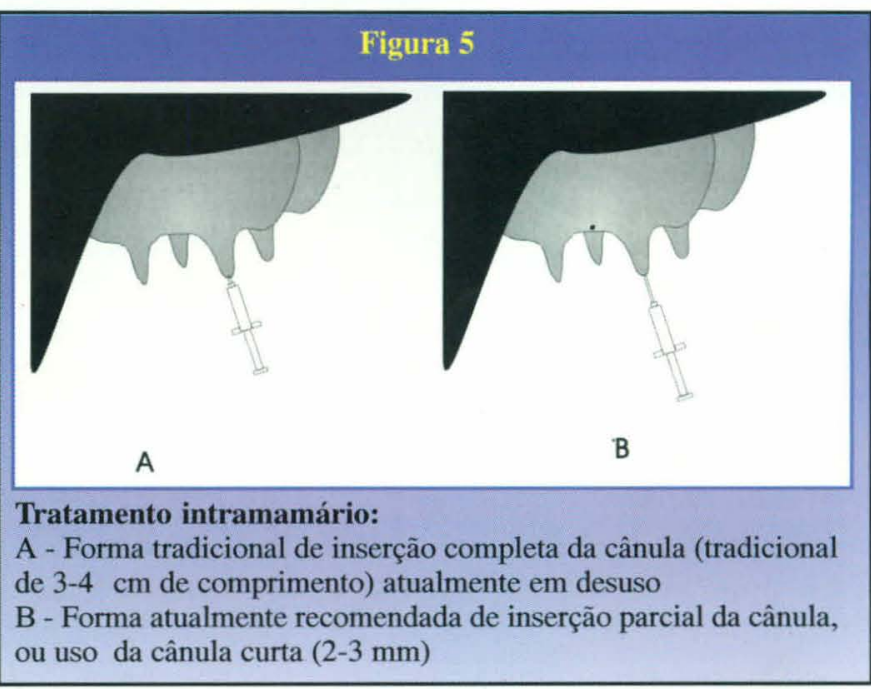

Figura 5: Tratamento intramamário; inserção parcial da cânula. 
Se as bactérias ou outros tipos de microrganismos, agentes etiológicos de mastite, como fungos e algas, superarem a barreira de queratina e penetrarem na glândula mamária, encontrarão elementos de defesa, que atuaram para impedir a instalação do processo, tais como, complemento, lisozima, lactoferrina, peroxidase e os macrófagos células fagocitárias que englobam e destroem microorganismos.

Outro importante mecanismo de defesa é a remoção mecânica pelos jatos de leite, quando o animal é bem ordenhado. Daí a recomendação de ordenhas a fundo, repetidas várias vezes ao dia, em casos de mastite clínica aguda, para auxiliar a remoção mecânica de microrganismos e também das toxinas produzidas e metabólitos inflamatórios, pois, ao lesar as células alveolares, ocorre a ativação da cascata da ácido aracdônico e há formação de mediadores do processo inflamatório: prostaglandinas e leucotrienos. Os mediadores liberados vão ter tanto ação benéfica quanto deletéria, havendo a necessidade do uso de antiinflamatórios, sendo que o grupo dos corticóides é contra-indicado, uma vez que estes suprimem também a resposta benéfica.

\section{Fatores ligados ao ambiente}

Condições ambientais, nutrição e funcionamento inadequado da ordenhadeira mecânica influenciam o desempenho do mecanismos naturais de defesa.

O "stress" térmico compromete a resposta imune, por exemplo, interfere com a migração dos PMN para o foco de infecção, a glândula infectada, e os linfócitos B, secretam menos anticorpos

Também deficiências em alguns minerais e vitaminas, na alimentação, comprometem o desempenho da resposta imune, tais como: deficiências em selênio e/ou vitamina E, vitamina A e/ou beta-caroteno. Entretanto é importante considerar que a forma correta e mais eficiente é um manejo nutricional adequado, o qual geralmente supre as necessidades evitando as deficiências alimentares como um todo. Assim, já foi demonstrado em estudo experimental, que o uso de suplementação com selênio em animais, em propriedade com bom manejo alimentar, não diferiu estatisticamente em relação à ocorrência de mastite do grupo controle, animais da mesma propriedade que não receberam a suplementação com este microelemento.

Por outro lado, o mal funcionamento da ordenhadeira mecânica, como por exemplo, vácuo elevado combinado com sobreordenha, afeta a integridade das células que revestem o canal do teto, prejudicam a camada de queratina, ou seja diminuindo a eficiência das barrei- ras mecânicas e químicas do teto, propiciam um aumento da ocorrência tanto de mastites contagiosas como as ambientais.

No controle da mastite ambiental por exemplo, uma medida de grande eficiência é alimentar os animais imediatamente após a ordenha, evitando que os mesmos se deitem antes do completo fechamento do esficter do teto. A oclusão total somente ocorre em cerca 45 minutos ou até mesmo, só 2 horas após a ordenha em alguns animais.

O manejo no período seco e o controle de artrópodes é também de fundamental importância, o que pode ser exemplificado pela chamada mastite de verão, causada por Actinomyces pyogenes que é transmitida principalmente por moscas, ocorrendo mais no período seco.

\section{Programas de Controle}

Os programas de controle de mastite (Figura 6) tem como objetivo a limitação da prevalência da mastite a níveis economicamente aceitáveis dentro das circunstâncias particulares a cada propriedade. A erradicação não se mostra como uma meta apropriada.

O programa deverá ser baseado em quatro aspectos fundamentais:

- -quanto à fonte de infecção, o seu diagnóstico, tratamento ou descarte;

- -em relação ao susceptível, nutrição, seleção de animais mais resistentes e higiene de ordenha;

- -em relação as vias de transmissão: higiene de ordenha e meio ambiente;

- - por último, porém o mais importante, a conscientização do problema aos produtores devido às perdas econômicas, e educação sanitária dos tratadores e ordenhadores (COSTA, 1991).

O primeiro passo do programa é verificar o "status" de mastite do rebanho antes de qualquer alteração do manejo (JACKSON, 1980). O seu sucesso dependerá da contínua aplicação das medidas de manejo específicas, com supervisão do veterinário e monitoramento dos índices de infecção e inflamação do rebanho (BRAMLEY \& DODD, 1984). Os métodos utilizados podem ser: tamis, contagem celular do leite (Prescot Breed, contagem celular eletrônica), contagem celular individual e/ ou do leite da pequena mistura, testes indiretos como California Mastitis Test (CMT), acompanhados de exames microbiológicos sempre que necessários e do registro de casos clínicos. (RADOSTITIS et al, 1994). 
Figura 6: Controle de Mastite

\section{CONTROLE DE MASTITE}

Em síntese um programa de controle de mastite deverá visar:

1. Reduzir as infecções pré-existentes.

2. Prevenir novas infecções.

3. Monitorar o nivel de mastite.

\section{Reduzir as infecções pré-existentes:}

1.1. Diagnóstico e tratamento precoce dos casos clínicos;

1.2. Tratamento de mastite sub-clínca na interrupção da lactação.

1.3. Descarte:

- Vacas com mais de 3 casos clínicos por lactação, que não respondem ao tratamento de "vaca seca", deverão ser descartadas.

\section{Prevenir novas infecções:}

2.1. Manejo e higiene de ordenha corretos;

- Manter úberes limpos;

- Ordenhar tetos limpos e secos (toalhas, descartáveis);

- Desligar o vácuo antes da remoção das teteiras

2.2. Desinfecção pós-ordenha adequada:

- Usar desinfetante recém preparado, com correta diluição;

- Aplicação correta, cobrindo todo o teto e todos os tetos;

- Usar de prefêrencia com emoliente( glicerina 5-10 \%);

- Evitar acúmulo de matéria orgânica, pois diminui o poder germicida.

2.3. Manutenção adequada do equipamento de ordenha:

- Revisão periódica do equipamento, pelo menos anual, e sempre que necessário.

- Chamar assistência técnica sempre que as teteiras escorregarem mais que 5 vezes a cada 100 vacas.

- Garantir uma pulsação adequada, mantendo a fase de massagem em pelo menos $15 \%$ do ciclo de pulsação.

\section{Monitoramento do nível de mastite:}

3.1. Monitoramento dos casos de mastite clínica

- Através do teste do tamis ou caneca preta realizado a cada ordenha;

- Manter o registro de todos os quartos tratados;

- Colher amostras antes do ínicio do tratamento;

- Respeitar o intervalo de uso do leite do animal em tratamento.

3.2. Monitorar o nível de mastite subclínica periódicamente

- Manter os registros atualizados, resultados do CMT ou contagem de células.

- Tratar no período seco, na última ordenha ao final da lactação;

- Havendo alta prevalência tratar mesmo em lactação.

3.3. Estabelecer as metas:

- Nivel de mastite clínica igual ou inferior a $1 \%$;

- Nível de mastite subclínica igual ou inferior a $15 \%$;

- Nivel de vacas récem-paridas com mastite menor que $10 \%$;

- Contagem celular abaixo de 250.000 células $/ \mathrm{ml}$.

OBS: Contagem celular abaixo de 100.000 é excelente;contagem celular acima de 400.000 ou mais de 30 casos clínicos por ano, indicam a necessidade de assistência especializada, para fazer análise da situação e estabelecer os pontos críticos e um program especifico de controle para a propriedade 


\section{SUMMARY}

Mastitis is an inflammation of the mammary gland that causes severe economic losses due to reduced milk production, expence on pharmaceuticals, veterinary care, discarding of milk after treatment and discarding of affected animals. This inflammatory process may have distinct origins, but all cases of economic importance are caused by microrganims. According to their origin and means of transmission, the main etiological agents were put together in two groups, contagious microorganisms (Streptococcus agalactiae, Staphylococcus sp, e Corynebacterium bovis) transmitted mainly during milking and environmental microorganisms (Streptococcus uberis, Enterobacteriaceae, fungos, algae of the genus Prototheca, etc.). Clinical mastitis is characterized by visible changes in mammary gland and/or in milk. Subclinical mastitis is characterized by reduction of milk production although no signs of inflammatory process may be seen. Mastitis control programs have the objective of limiting the prevalence of mastitis to economic acceptable levels according to the particular features of each dairy farm. The program is based in four aspects: source of infection - diagnosis, treatment or discarding of the animals; susceptible - nutrition, selection of more resistant animals and milking hygiene; means of transmission - milking hygiene and environmental hygiene; awareness of the problem by the producers due to the economic losses and sanitary education of the dairyman. The estimated economic losses due to mastitis on brazilian dairy herds were around US\$332/ cow/year, higher than the estimated losses in the United States, that were around US\$200/cow/year.

Uniterms: mastitis, bovine, mammary gland, microorganisms, control

\section{REFERÊNCIAS BIBLIOGRÁFICAS}

1 - BRAMLEY, J.A.; DODD, F.H. Reviews of the progress of dairy science: mastitis control progress and prospects Journal Dairy Research, v.51, p.481-512, 1984

2 - COSTA, E. O. da, Importância econômica da mastite infecciosa bovina. Revista Comunicações Científica Faculdade Medicina Veterinária Zootecnia USP, v.15, n 1, p.21-26, 1991.

3 - COSTA, E. O. da; COUTINHO, S. D.; CASTILHO, W.; TEIXEIRA, C. M.; GAMBALE, W.; GANDRA, C. R. P. Etiologia bacteriana da mastite bovina, no Estado de São Paulo, Brasil. Revista de Microbiologia, v.17, n.2, p.107-112, 1986

4 - COSTA, E.O.; BENITES, N.R.; MELVILLE, P.A.; PARDO, R.B.; RIBEIRO, A.R.; WATANABE, E.T. Estudo etiológico da mastite clínica bovina. Revista Brasileira de Medicina Veterinária, v.17, n.4, p.156-8, 1995.

5 - COSTA, E.O.; BENITES, N.R.; MELVILLE, P.A.; PARDO, R.B.; RIBEIRO, A.R.; WATANABE, E.T. Estudo etiológico da mastite clínica bovina. Revista Brasileira de Medicina Veterinária, v.17, n.4, p.156-8, 1995.

6 - COSTA, E.O.; GANDRA, C.R.P.; GAMBALE, W; PIRES, M.F.C.; COUTINHO, S. D. A.; CASTILHO, W. Survey of bovine mycotic mastitis in dairy herds in the State of São Paulo, Brazil. Mycopathologia, v.124, p.13-7, 1993.

7 - COSTA, E.O.; MELVILLE, P.A.; RIBEIRO, A.R.; WATANABE, E.T.; WHITE, C.R.; PARDO, R.B. Indices de mastite bovina clínica e subclínica nos Estados de São Paulo e Minas Gerais. Revista Brasileira de Medicina Veterinária, v.17, n.5, p.215-7, 1995.

8 - COSTA, E.O.; RIBEIRO, A.R.; WATANABE, E.T; SILVA, J.A.B.; GARINO JR., F.; BENITES, N.R.; HORIUTI, N.R. Costs of subclinical mastitis and their prevention in dairy herds. In: PAN AMERICAN CONGRESS ON MASTITIS CONTROL AND MILK QUALITY. Mérida Yucatán, 1998. Proceedings. p.190-191. 1998.

9 - CULLOR, J.S. The control, treatment, and prevention of the various types of bovine mastitis. Veterinary Medicine, n. 88, p. 571-9. 1993.

10 - DU PREEZ, J.H.; GIESECKE, W.H. Mastitis. In: COETZER, J.A.W.; THOMSON, G.R. Infectious diseases of livestock. Oxford University Press, 1994. v.2. Chap. 190. p.1564-1595.
11 - ELVINGER, F. i NATZKE, R.P. Elements of mastitis control In large dairy herd management. Champaign, Van Hom \& Wilcox, 1992, p.440-447.

12 - JACKSON, E.R. The role of the veterinary practicioner in mastitis control. Mastitis Control and Herd Managment, p.253265, 1980.

13 - MILLER, G.Y.; BARTLETT, P.C.; LANCE S.E.; ANDERSON, J., HEIDER, L.E. Costs of clinical mastitis and mastitis prevention in dairy herds. Journal of American Veterinary Medical Association, v.202, n. 8, p. 1230-6, 1993.

14 - PANKEY,J.M. i DRECHSLER,P.A. Evolution of udder higiene: Premilking teat sanitation, Veterinary Clinics of North America, v.9, n.3, p.519-30, nov., 1993.

15 - PHILPOT, W.N. Economics of mastitis control. Symposium on mastitis. Veterinary Clinics of North America, v.6, p.23345, 1984.

16 - PONCE, H.; MELVILLE, P.A.; RIBEIRO, A.R.; SÁ FILHO, R.; COSTA, E.O. Influência de processos de interrupção da lactação sobre a ocorrência de mastite. Arquivo Brasileiro de Medicina Veterinária e Zootecnia, v.48, n.4, p.481-4, 1996.

17 - RADOSTITIS,O.M.; LESLIE, K. E i FETROW, J.Herd health; food, animal, production, medicine. 2. ed. Philadelphia, W.B. Saunders. 1994. p. 229-76.

18 - RENEAU, J.K. Clinical mastitis records in production medicine programs Compendiun on Continuing Education-Food Animal Practice, v.15, n. 03, march 1993.

19 - RIBEIRO, A.R.; WATANABE; E.T.; GARINO JÚNIOR; F.; SILVA, J.A.B.; THIERS; F.O.; COSTA, E.O. Avaliação "in vitro" de diversos produtos para anti-sepsia dos tetos frente às cepas de microrganismos isoladas de casos de mastite bovina. In: CONGRESSO BRASILEIRO DE MEDICINA VETERINÁRIA, 25, Gramado, Rio Grande do Sul, p. 280 .

20 - SCHALM, O.W.; CARROLL, E. J.; JAIN, N.C. In. Bovine mastitis , Philadelphia, 1971, Lea \& Febiger. p. 94 -127. 